\title{
Antibiotic prophylaxis: different practice patterns within and outside the United States
}

\author{
This article was published in the following Dove Press journal: \\ Clinical Ophthalmology \\ 28 January 2016 \\ Number of times this article has been viewed
}

\author{
Stephen G Schwartz' \\ Andrzej Grzybowski² \\ Harry W Flynn Jr' \\ 'Department of Ophthalmology, \\ Bascom Palmer Eye Institute, \\ University of Miami Miller School \\ of Medicine, Miami, FL, USA; \\ 2Department of Ophthalmology, \\ Poznan City Hospital, Poznan, Poland
}

\begin{abstract}
Endophthalmitis remains a rare but important cause of visual loss. Prophylaxis strategies are important to reduce rates of endophthalmitis after cataract surgery, intravitreal injection, and other procedures. There is substantial variability between the US and the rest of the world. During cataract surgery, intracameral antibiotics are commonly used in many nations, especially in Europe, but are less commonly used in the US. A randomized clinical trial from the European Society of Cataract and Refractive Surgeons reported an approximately fivefold reduction in endophthalmitis rates associated with intracameral cefuroxime but these results are controversial. There are no randomized clinical trials regarding endophthalmitis associated with intravitreal injection. Topical antibiotics are commonly used in many nations, but are less commonly used in the US. At this time, there is no global consensus and it appears unlikely that additional major clinical trials will conclusively define the optimal endophthalmitis prophylaxis techniques.
\end{abstract}

Keywords: cataract surgery, endophthalmitis, intracameral antibiotic, intravitreal injection, prophylaxis

\section{Introduction}

Despite continuing advances in ophthalmic care, endophthalmitis remains a rare but potentially serious complication of intraocular procedures. Visual outcomes may be poor despite prompt and appropriate therapy. Therefore, risk reduction strategies are especially important to improve overall patient outcomes. ${ }^{1}$ These practices may vary substantially between nations, perhaps due to the relative lack of evidence from randomized clinical trials (RCTs).

There exists broad agreement about certain practices. For example, povidone-iodine antisepsis is the only technique to reach category II evidence in reducing endophthalmitis rates ${ }^{2}$ and is generally used before intraocular surgery and intravitreal injection ${ }^{3}$ in all nonallergic patients in most nations.

However, other practices are controversial and are used differently in different nations. These may be divided into endophthalmitis prophylaxis strategies for cataract surgery and for intravitreal injections. These two categories of endophthalmitis have not only many similarities but also important differences in risk factors, clinical features, and microbiological profiles. Endophthalmitis following intravitreal injections is more likely to present earlier and to result in worse outcomes. Microbial isolates from intravitreal injections are more likely to contain Streptococcus species and other oral flora. ${ }^{4-6}$

The present manuscript reviews the available literature on antibiotic prophylaxis of endophthalmitis with cataract surgery and intravitreal injection, emphasizing differences between the US and other parts of the world. Relevant articles were reviewed,
Correspondence: Stephen G Schwart Department of Ophthalmology, Bascom Palmer Eye Institute, 3880 Tamiami Trail North, Naples, FL 34103, USA

$\mathrm{Tel}+\mathrm{I} 2396593937$

Fax +I 2396593982

Email sschwartz2@med.miami.edu 
especially those comparing rates of endophthalmitis following cataract surgery with and without intracameral antibiotics as well as endophthalmitis following intravitreal injection with and without topical antibiotics. This is intended to provide a concise summary for the practicing ophthalmologist but is not a systematic review; therefore, it is possible that some relevant studies may have been missed.

\section{Antibiotic prophylaxis with cataract surgery}

The reported incidence rates of acute-onset postoperative endophthalmitis (defined as presenting within 6 weeks) (Figure 1) range from approximately $0.03 \%$ to $0.2 \%$ in many large series. ${ }^{1,7}$ Using Medicare claims data, the rate in the US was reported to be approximately $0.1 \%$ in $2003-2004$; it is likely that the majority of these patients did not receive intracameral antibiotics. ${ }^{8}$ In contrast, the Swedish National Cataract Register reported a rate of $0.048 \%$ in $2002-2004$, and most of these patients did receive intracameral cefuroxime. ${ }^{9}$ However, comparing cohorts on different continents, even during a similar time period, is problematic, because many other factors may have influenced these rates, including differences in patient demographics, surgeons, equipment, techniques, and unknown factors.

The European Society of Cataract and Refractive Surgeons (ESCRS) performed a large multicenter prospective RCT and reported that intracameral injection of cefuroxime was associated with an approximately fivefold reduction in endophthalmitis rates following phacoemulsification. ${ }^{10}$ A specific criticism of the ESCRS study was the high rate of endophthalmitis in patients not randomized to receive intracameral cefuroxime (the rates of "proven" endophthalmitis in these two groups were $0.18 \%$ and $0.23 \%$ ), which may have exaggerated the apparent treatment benefits. In addition,

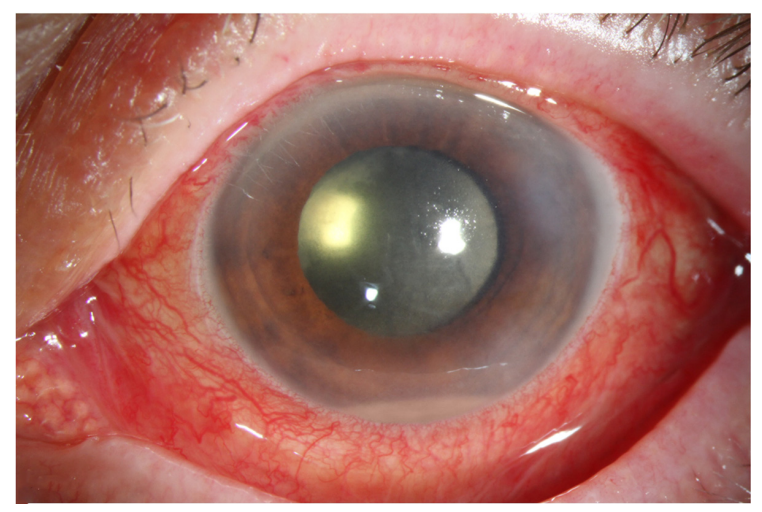

Figure I External photograph, left eye, demonstrating acute-onset postoperative endophthalmitis following cataract surgery.

Notes: Vitreous cultures isolated Staphylococcus epidermidis. Following treatment, visual acuity improved to $20 / 25$. this study, which enrolled patients during 2003-2006, used levofloxacin as the topical antibiotic. It has been suggested that newer and more efficacious fourth-generation fluoroquinolones, such as moxifloxacin and gatifloxacin, might have reduced the apparent benefits of intracameral cefuroxime in this trial. ${ }^{11}$ Favorable results using various intracameral antibiotics (including cefuroxime, cefazolin, moxifloxacin, and vancomycin) were subsequently reported in the UK, ${ }^{12}$ Spain, ${ }^{13-15}$ France, ${ }^{16}$ Singapore,${ }^{17}$ the US,,${ }^{18,19}$ Sweden, ${ }^{20}$ Japan, ${ }^{21}$ Portugal, ${ }^{22}$ Ireland, ${ }^{23}$ Israel, ${ }^{24}$ and other nations (Table 1). Alternatively, two large series of cataract surgeries from Canada ${ }^{25}$ and India ${ }^{26}$ reported no significant benefits associated with intracameral antibiotics. Of note, none of these later series were RCTs. Rather, they were retrospective reviews in which two cohorts were compared. The first cohort was generally an earlier group of patients treated without intracameral antibiotics, and the second cohort was generally a later group of patients treated after an institution's protocol was changed and antibiotics were initiated. When interpreting these results, it is important to consider that the two groups of patients were not treated at the same time; generally the antibiotic-treated patients underwent surgery in later years than the nonantibiotic-treated patients. Therefore, there may be important differences between the two cohorts other than the use of intracameral antibiotics, which also may have impacted the endophthalmitis rates. These differences may include differences in surgeons, equipment, techniques, or unknown factors.

Among these later series, rates of endophthalmitis in the cohorts not treated with intracameral antibiotics were also relatively high. In eight out of these 15 series, rates of endophthalmitis in the nonantibiotic-treated eyes (operated earlier in time) were greater than $0.2 \%$, or higher than the nonantibiotic-treated eyes in the ESCRS RCT. Again, these relatively high rates may have exaggerated the apparent treatment benefits of intracameral antibiotics. In comparison, the reported rate of endophthalmitis without the use of intracameral antibiotics from the Bascom Palmer Eye Institute during a comparable time period (2002-2009) was $0.028 \%$ in 28,568 surgeries. ${ }^{27}$ This rate is similar to the rates reported in the ESCRS study for patients randomized to receive intracameral cefuroxime $(0.025 \%$ and $0.050 \%$ ) as well as the rates reported in most of the eyes treated with intracameral antibiotics in the cohort studies.

Although many studies report favorable results, there are other concerns about intracameral antibiotics, especially in nations (such as the US) in which an approved, prepackaged antibiotic indicated for intracameral use is not available and compounded antibiotics must be used. These concerns include risks of dilution errors and contaminants, 
Table I Selected reports of intracameral antibiotics in cataract surgery

\begin{tabular}{|c|c|c|c|c|c|c|}
\hline Series & $\mathbf{n}$ & Nation & Antibiotics & $\begin{array}{l}\text { Rate without } \\
\text { intracameral } \\
\text { antibiotics (\%) }\end{array}$ & $\begin{array}{l}\text { Rate with } \\
\text { intracameral } \\
\text { antibiotics (\%) }\end{array}$ & $P$-value \\
\hline ESCRS $10, *$ & 16,603 & Multiple & Cefuroxime & $0.18-0.23$ & $0.025-0.050$ & 0.005 \\
\hline Yu-Wai-Man et al ${ }^{12}$ & 36,743 & UK & Cefuroxime & 0.14 & 0.046 & 0.0068 \\
\hline Garat et $\mathrm{al}^{13}$ & 18,579 & Spain & Cefazolin & 0.39 & 0.032 & $<0.0000001$ \\
\hline Barreau et al ${ }^{16}$ & 5,115 & France & Cefuroxime & 1.24 & 0.044 & $<0.0001$ \\
\hline Romero-Aroca et a $\left.\right|^{14}$ & 25,001 & Spain & Cefazolin & 0.63 & 0.05 & $<0.001$ \\
\hline Tan et $\mathrm{al}^{17}$ & 50,177 & Singapore & Cefazolin & 0.064 & 0.01 & $<0.001$ \\
\hline Friling et $\mathrm{a}^{20}$ & 464,996 & Sweden & Cefuroxime & 0.39 & 0.027 & $<0.001$ \\
\hline Matsuura et $\mathrm{al}^{21}$ & 34,752 & Japan & Moxifloxacin & 0.051 & 0.015 & 0.037 \\
\hline Shorstein et $\mathrm{al}^{18}$ & 16,264 & USA & Multiple & 0.31 & $0.014-0.14$ & NR \\
\hline Rodriguez-Caravaca et al ${ }^{15}$ & 19,463 & Spain & Cefuroxime & 0.59 & 0.039 & $<0.05$ \\
\hline Beselga et $\mathrm{al}^{22}$ & 15,689 & Portugal & Cefuroxime & 0.26 & 0 & $<0.05$ \\
\hline Rudnisky et $\mathrm{a}^{25, * *}$ & 75,318 & Canada & Multiple & 0.03 & 0.03 & 0.90 \\
\hline Herrinton et al ${ }^{19}$ & 315,246 & USA & Multiple & $0.07-0.14$ & 0.044 & $N R$ \\
\hline Katz et $\mathrm{a}^{24}$ & 56,094 & Israel & Cefuroxime & 0.083 & 0.034 & 0.03 \\
\hline Rahman and Murphy ${ }^{23}$ & 16,975 & Ireland & Cefuroxime & 0.49 & 0.06 & $<0.0001$ \\
\hline Sharma et $\mathrm{a}^{26, * *}$ & 15,122 & India & Cefuroxime & 0.16 & 0.11 & 0.38 \\
\hline
\end{tabular}

Notes: *Randomized clinical trial. **Series reporting no significant difference in endophthalmitis rates.

Abbreviations: ESCRS, European Society of Cataract and Refractive Surgeons; NR, not reported.

increased costs, increased bacterial drug resistance, and other complications. ${ }^{28}$ Accidental overdoses of intracameral cefuroxime have been associated with uveitis, macular edema, and retinal vascular leakage. ${ }^{29}$ Postoperative hemorrhagic occlusive retinal vasculitis has been associated with intracameral vancomycin. ${ }^{30}$

In 2012, the European Medicines Agency approved Aprokam (Thea Pharmaceuticals, Clermont-Ferrand, France), a prepackaged cefuroxime indicated for single use during cataract surgery, which is now available in 26 European nations. The availability of this product alleviates many of the concerns about compounded antibiotics but Aprokam is not universally used, even in nations where it is available. The ESCRS conducted a telephone survey of 250 members, in which the interviews were completed by 193 surgeons (77\%) from 31 European nations in 2012. Intracameral antibiotics were used "always" or "usually" by $74 \%$ of respondents; of the $26 \%$ who did not routinely use intracameral antibiotics, $52 \%$ gave "there is no need" as their reason for not using them. ${ }^{31}$

A review of the relevant literature from nine European countries, published in 2013, reported broad use of povidoneiodine or chlorhexidine antisepsis, but wide variations in the use of intracameral antibiotics. For example, intracameral antibiotics were used almost universally in Sweden, where their omission was regarded as unethical. Similarly, intracameral injection of cefuroxime was "strongly recommended" and used in a majority of cataract surgeries in France. However, the use of intracameral antibiotics was much lower and varied substantially in the UK, Spain, Germany, Belgium,
Italy, the Netherlands, and Poland. ${ }^{32}$ In addition, a survey of 386 Japanese cataract surgeons, conducted in 2014, reported the addition of antibiotics to the irrigating bottle in $22 \%$ and the injection of intracameral antibiotics in $7 \%{ }^{33}$

The American Society of Cataract and Refractive Surgery (ASCRS) conducted an online poll of 7,677 members in 2014. The poll was completed by 1,147 members (15\%), of whom 65\% were from the US, 13\% from Latin America, and 9\% from Europe. Intracameral antibiotics were injected at the conclusion of surgery by $36 \%$ of all respondents; these percentages were $30 \%$ of US respondents and $70 \%$ of European respondents. Half (50\%) of all respondents reported using any type of intracameral antibiotic, but only $16 \%$ of these respondents used antibiotics in the irrigating solution. The most common reported antibiotics directly injected were moxifloxacin (mixed from commercial Vigamox, 29\%) and vancomycin $(22 \%)$; the most commonly reported antibiotic mixed into the irrigating solution was vancomycin (15\%). Of respondents from nations (including the US) without access to a commercially available formulation of cefuroxime for intracameral injection, $69 \%$ reported that they would use this drug if it were approved and if the cost were reasonable. ${ }^{34}$

\section{Antibiotic prophylaxis with intravitreal injections}

The reported incidence rates of endophthalmitis following intravitreal injection of antivascular endothelial growth factor agents range from $\sim 0.02 \%$ to $0.3 \%$ per injection. ${ }^{35}$ Because most patients are treated with a series of injections, the cumulative rate of endophthalmitis per patient is higher. 
Unlike the situation with cataract surgery, in which the ESCRS conducted a RCT, there are no major RCTs evaluating alternative intravitreal injection techniques. Therefore, an expert committee published guidelines in $2004^{36}$ and revised these guidelines in 2014. ${ }^{3}$ These consensus guidelines include deferring injections in the presence of active external infection, reducing aerosolized droplets containing oral contaminants, and the use of topical povidone-iodine before injection. However, these guidelines allow for substantial variability in technique, including the setting in which the injections are performed (clinic room vs operating room) and the use of prophylactic topical antibiotics. In addition, there are many other factors that may influence endophthalmitis rates for which there is no consensus, including the use of facemasks, surgical drapes, eyelid speculums, conjunctival displacement, and location of injection site (superior vs inferior, rotating sites).

In the US, intravitreal injections are generally performed in a clinic setting, but injections are performed in an operating room setting in many European nations. A study compared 8,647 injections performed by a US-based surgeon in a clinic setting versus 3,063 injections performed by an Italian surgeon in an operating room. The endophthalmitis rates were $0.035 \%$ in the clinic and $0.065 \%$ in the operating room, which were not significantly different. ${ }^{37}$

There also appear to be differences between nations regarding the use of topical antibiotics before or after intravitreal injections. ${ }^{38}$ Multiple studies (but no RCTs) from the US, ${ }^{39-43}$ Canada, ${ }^{44}$ Iran, ${ }^{45,46}$ and Korea ${ }^{47}$ have reported no statistically significant differences in endophthalmitis rates between eyes treated with antibiotics or not (Table 2). An additional series of 316,576 intravitreal injections in France did not specifically report rates of endophthalmitis with and without antibiotic prophylaxis but reported an overall rate of $0.021 \%$ and that "prophylaxis with an antibiotic or antiseptic" was associated with increased rates of endophthalmitis in both univariate $(P=0.21)$ and multivariate $(P=0.001)$ analyses. ${ }^{48}$ Alternatively, a series of 11,450 injections from France reported a rate of endophthalmitis of $0.03 \%$ in antibiotic-treated eyes and $0.23 \%$ in nontreated eyes $(P=0.024) .{ }^{49}$ A potential criticism of this study is the relatively high rate of endophthalmitis in nonantibiotic-treated eyes, which may have exaggerated the apparent benefit of antibiotics in this one study.

The American Society of Retina Specialists (ASRS) annual Preferences and Trends (PAT) survey gives information about differences in technique between US members and international members. The questions change from year to year. The 2013 survey reported that injections were performed more commonly in a surgery center, hospital, or other location (rather than the clinic) by international members than by US members (57.3\% vs $1.8 \%$ ). Topical antibiotics were used with intravitreal injection more commonly by international members than by US members ( $70.9 \%$ vs $21.8 \%$ ). Facemasks were used more commonly by international members than by US members on the injecting physician $(49.1 \%$ vs $14.3 \%)$ and on both the physician and the patient ( $16.8 \%$ vs $3.7 \%){ }^{50}$

The 2014 ASRS PAT survey reported generally similar usage rates of an eyelid speculum during intravitreal injections between US members and international members. ${ }^{51}$ The 2015 ASRS PAT survey reported persistence of the disparity between US members and international members regarding topical antibiotics for intravitreal injections: only $9.5 \%$ of US members reported using topical antibiotics, as opposed to $60.6 \%$ of international members. ${ }^{52}$

\section{Conclusion}

There are currently two major apparent areas of discrepancy between US and non-US ophthalmologists regarding endophthalmitis prophylaxis. US ophthalmologists appear relatively less likely to use intracameral antibiotics during

Table 2 Selected reports of topical antibiotics with intravitreal injection

\begin{tabular}{|c|c|c|c|c|c|}
\hline Series & $\mathbf{n}$ & Nation & $\begin{array}{l}\text { Rate without topical } \\
\text { antibiotics (\%) }\end{array}$ & $\begin{array}{l}\text { Rate with topical } \\
\text { antibiotics (\%) }\end{array}$ & $P$-value \\
\hline Bhatt et $\mathrm{al}^{39}$ & 4,767 & USA & 0.20 & 0.22 & 0.75 \\
\hline Bhavsar et $\mathrm{al}^{40}$ & 8,027 & USA & 0.03 & 0.13 & 0.25 \\
\hline Cheung et a $\left.\right|^{44}$ & 15,895 & Canada & 0.038 & $0.06 \mathrm{I}-0.084$ & NR \\
\hline Falavarjani et $\mathrm{al}^{45}$ & 5,901 & Iran & 0 & 0.10 & 0.18 \\
\hline Park et $\mathrm{al}^{47}$ & 17,332 & Korea & 0.035 & 0 & 0.81 \\
\hline Ramel et $\mathrm{al}^{49, *}$ & 11,450 & France & 0.2 & 0.03 & 0.024 \\
\hline Storey et $\mathrm{a}^{41}$ & $117,17 \mid$ & USA & 0.032 & 0.049 & NR \\
\hline Falavarjani et $\mathrm{a}^{46}$ & 8,037 & Iran & 0 & 0.01 & 0.30 \\
\hline Gregori et $\mathrm{al}^{43}$ & 121,285 & USA & 0.02 & 0.013 & 0.38 \\
\hline Meredith et $\mathrm{al}^{42}$ & 18,509 & USA & 0.15 & $0.04-0.08$ & 0.20 \\
\hline
\end{tabular}

Note: *Series reporting significant difference in endophthalmitis rates.

Abbreviation: NR, not reported. 
cataract surgery and relatively less likely to use topical antibiotics with intravitreal injections. There may be many reasons for these differences, but it is important to note that there is very little pertinent information available from RCTs.

In the 2014 ASCRS survey, ${ }^{34}$ the major reported reason for not using intracameral antibiotics during cataract surgery was the lack of a commercially available prepackaged antibiotic for this indication. However, many US cataract surgeons simply believe that intracameral antibiotics are unnecessary, based on concerns about the ESCRS and other studies as well as risks of dilution errors, toxicity, and selection of drugresistant organisms. Should a commercially manufactured, approved intracameral antibiotic become available, it is reasonable to suspect that it would be adopted by more US surgeons, although the precise number cannot be predicted. Of note, the ASCRS Clinical Cataract Committee strongly supports the investigation towards an approved commercial antibiotic preparation which may improve the safety of intracameral antibiotics. ${ }^{7}$

Based on many newer published series of intravitreal injections without topical antibiotics, it is possible that non-US ophthalmologists will increasingly forgo topical antibiotics with intravitreal injections. The majority of the published trials (although no RCTs) have reported no apparent benefit associated with topical antibiotics in this setting. There is some evidence that topical antibiotics may actually increase the endophthalmitis rate after intravitreal injections, perhaps by unfavorably altering conjunctival flora. ${ }^{38}$ Continued good outcomes without topical antibiotics in this setting may encourage non-US ophthalmologists to stop using them.

At the present time, there is no global consensus regarding endophthalmitis prophylaxis practices, and it appears unlikely that additional major RCTs will be conducted to conclusively define the roles of intracameral antibiotics in cataract surgery and topical antibiotics in intravitreal injections.

\section{Acknowledgments}

Partially supported by the National Institutes of Health Center Core Grant P30EY014801 and an unrestricted grant from Research to Prevent Blindness, New York, NY.

\section{Disclosure}

The authors report no conflicts of interest in this paper.

\section{References}

1. Vaziri K, Schwartz SG, Kishor K, Flynn HW Jr. Endophthalmitis: state of the art. Clin Ophthalmol. 2015;9:95-108.
2. Ciulla TA, Starr MB, Masket S. Bacterial endophthalmitis prophylaxis for cataract surgery: an evidence-based update. Ophthalmology. 2002;109(1):13-24.

3. Avery RL, Bakri SJ, Blumenkranz MS, et al. Intravitreal injection technique and monitoring: updated guidelines of an expert panel. Retina. 2014;34(Suppl 12):S1-S18.

4. Simunovic MP, Rush RB, Hunyor AP, Chang AA. Endophthalmitis following intravitreal injection versus endophthalmitis following cataract surgery: clinical features, causative organisms and post-treatment outcomes. Br J Ophthalmol. 2012;96(6):862-866.

5. McCannell CA. Meta-analysis of endophthalmitis after intravitreal injection of anti-vascular endothelial growth factor agents: causative organisms and possible prevention strategies. Retina. 2011;31(4): 654-661.

6. Chen E, Lin MY, Cox J, Brown DM. Endophthalmitis after intravitreal injection: the importance of Viridans streptococci. Retina. 2011;31(8):1525-1533.

7. Braga-Mele R, Chang DF, Henderson BA, et al. Intracameral antibiotics: safety, efficacy, and preparation. J Cataract Refract Surg. 2014; 40(12):2134-2142.

8. Keay L, Gower EW, Cassard SD, Tielsch JM, Schein OD. Postcataract surgery endophthalmitis in the United States: analysis of the complete 2003 to 2004 Medicare database of cataract surgeries. Ophthalmology. 2012;119(5):914-922.

9. Lundstrom M, Wejde G, Stenevi U, Thorburn W, Montan P. Endophthalmitis after cataract surgery: a nationwide prospective study evaluating incidence in relation to incision type and location. Ophthalmology. 2007; 114(5):866-870.

10. ESCRS Endophthalmitis Study Group. Prophylaxis of postoperative endophthalmitis following cataract surgery: results of the ESCRS multicenter study and identification of risk factors. $J$ Cataract Refract Surg. 2007;33(6):978-988.

11. O’Brien TP, Arshinoff SA, Mah FS. Perspectives on antibiotics for postoperative endophthalmitis prophylaxis: potential role of moxifloxacin. $J$ Cataract Refract Surg. 2007;33(10):1790-1800.

12. Yu-Wai-Man P, Morgan SJ, Hildreth AJ, Steel DH, Allen D. Efficacy of intracameral and subconjunctival cefuroxime in preventing endophthalmitis after cataract surgery. J Cataract Refract Surg. 2008; 34(3):447-451.

13. Garat M, Moser CL, Martin-Baranera M, Alonso-Tarres C, AlvarezRubio L. Prophylactic intracameral cefazolin after cataract surgery: endophthalmitis risk reduction and safety results in a 6-year study. $J$ Cataract Refract Surg. 2009;35(4):637-642.

14. Romero-Aroca P, Mendez-Marin I, Salvat-Serra M, Fernández-Ballart J, Almena-Garcia M, Reyes-Torres J. Results at seven years after the use of intracamerular cefazolin as an endophthalmitis prophylaxis in cataract surgery. BMC Ophthalmol. 2012;12:2. doi:10.1186/1471-2415-12-2.

15. Rodriguez-Caravaca G, Garcia-Saenz MC, Villar-Del Campo MC, Andres-Alba Y, Arias-Puente A. Incidence of endophthalmitis and impact of prophylaxis with cefuroxime on cataract surgery. J Cataract Refract Surg. 2013;39(9):1399-1403.

16. Barreau G, Mounier M, Marin B, Adenis JP, Robert PY. Intracameral cefuroxime injection at the end of cataract surgery to reduce the incidence of endophthalmitis: French study. J Cataract Refract Surg. 2012;38(8):1370-1375.

17. Tan CS, Wong HK, Yang FP. Epidemiology of postoperative endophthalmitis in an Asian population: 11-year incidence and effect of intracameral antibiotic agents. J Cataract Refract Surg. 2012;38(3): 425-430.

18. Shorstein NH, Winthrop KL, Herrinton LJ. Decreased postoperative endophthalmitis rate after institution of intracameral antibiotics in a Northern California eye department. J Cataract Refract Surg. 2013;39(1): $8-14$.

19. Herrinton LJ, Shorstein NH, Paschal JF, et al. Comparative effectiveness of antibiotic prophylaxis in cataract surgery. Ophthalmology. Epub 2015 Oct 9 . 
20. Friling E, Lundstrom M, Stenevi U, Montan P. Six-year incidence of endophthalmitis after cataract surgery: Swedish national study. J Cataract Refract Surg. 2013;39(1):15-21.

21. Matsuura K, Miyoshi T, Suto C, Akura J, Inoue Y. Efficacy and safety of prophylactic intracameral moxifloxacin injection in Japan. J Cataract Refract Surg. 2013;39(11):1702-1706.

22. Beselga D, Campos A, Castro M, et al. Postcataract surgery endophthalmitis after introduction of the ESCRS protocol: a 5-year study. Eur J Ophthalmol. 2014;24(4):516-519.

23. Rahman N, Murphy CC. Impact of intracameral cefuroxime on the incidence of postoperative endophthalmitis following cataract surgery in Ireland. Ir J Med Sci. 2015;184(2):395-398.

24. Katz G, Blum S, Leeva O, et al. Intracameral cefuroxime and the incidence of post-cataract endophthalmitis: an Israeli experience. Graefes Arch Clin Exp Ophthalmol. 2015;253(10):1729-1733.

25. Rudnisky CJ, Wan D, Weis E. Antibiotic choice for the prophylaxis of post-cataract extraction endophthalmitis. Ophthalmology. 2014; 121(4):835-841.

26. Sharma S, Sahu SK, Dhillon V, Das S, Rath S. Reevaluating intracameral cefuroxime as a prophylaxis against endophthalmitis after cataract surgery in India. $J$ Cataract Refract Surg. 2015;41(2):393-399.

27. WykoffCC, Parrott MB, Flynn HW Jr, Shi W, Miller D, Alfonso EC. Nosocomial acute-onset postoperative endophthalmitis at a university teaching hospital (2002-2009). Am J Ophthalmol. 2010;150(3):392-398.

28. Schimel AM, Alfonso EC, Flynn HW Jr. Endophthalmitis prophylaxis for cataract surgery: are intracameral antibiotics necessary? JAMA Ophthalmol. 2014;132(11):1269-1270.

29. Delyfer MN, Rougier MB, Leoni S, et al. Ocular toxicity after intracameral injection of very high doses of cefuroxime during cataract surgery. $J$ Cataract Refract Surg. 2011;37(2):271-278.

30. Witkin AJ, Shah AR, Engstrom RE, et al. Postoperative hemorrhagic occlusive retinal vasculitis: expanding the clinical spectrum and possible association with vancomycin. Ophthalmology. 2015;122(7):1438-1451.

31. Barry P. Adoption of intracameral antibiotic prophylaxis of endophthalmitis following cataract surgery: update on the ESCRS Endophthalmitis Study. J Cataract Refract Surg. 2014;40(1):138-142.

32. Behndig A, Cochener B, Guell JL, et al. Endophthalmitis prophylaxis in cataract surgery: overview of current practice patterns in 9 European countries. J Cataract Refract Surg. 2013;39(9):1421-1431.

33. Matsuura K, Mori T, Miyamoto T, et al. Survey of Japanese ophthalmic surgeons regarding perioperative disinfection and antibiotic prophylaxis in cataract surgery. Clin Ophthalmol. 2014;8:2013-2018.

34. Chang DF, Braga-Mele R, Henderson BA, et al. Antibiotic prophylaxis of postoperative endophthalmitis after cataract surgery: results of the 2014 ASCRS member survey. J Cataract Refract Surg. 2015;41(6): 1300-1305.

35. Fileta JB, Scott IU, Flynn HW Jr. Meta-analysis of infectious endophthalmitis after intravitreal injection of anti-vascular endothelial growth factor agents. Ophthalmic Surg Lasers Imaging Retina. 2014; 45(2):143-149.

36. Aiello LP, Brucker AJ, Chang S, et al. Evolving guidelines for intravitreous injections. Retina. 2004;24(5 Suppl):S3-S19.
37. Tabandeh H, Boscia F, Sborgia A, et al. Endophthalmitis associated with intravitreal injections: office-based setting and operating room setting. Retina. 2014;34(1):18-23.

38. Schwartz SG, Flynn Jr HW, Grzybowski A. Controversies in topical antibiotics use with intravitreal injections. Curr Pharm Des. 2015; 21(32):4703-4706

39. Bhatt SS, Stepien KE, Joshi K. Prophylactic antibiotic use after intravitreal injection: effect on endophthalmitis rate. Retina. 2011; 31:2032-2036.

40. Bhavsar AR, Stockdale CR, Ferris FL, et al. Update on risk of endophthalmitis after intravitreal drug injections and potential impact of elimination of topical antibiotics. Arch Ophthalmol. 2012; 130(6):809-810.

41. Storey P, Dollin M, Pitcher J, et al. The role of topical antibiotic prophylaxis to prevent endophthalmitis after intravitreal injection. Ophthalmology. 2014;121(1):283-289.

42. Meredith TA, McCannel CA, Barr C, et al. Postinjection endophthalmitis in the comparison of age-related macular degeneration treatments trials (CATT). Ophthalmology. 2015;122(4):817-821.

43. Gregori NZ, Flynn HW Jr, Schwartz SG, et al. Current infectious endophthalmitis rates after intravitreal injections of anti-vascular endothelial growth factor agents and outcomes of treatment. Ophthalmic Surg Lasers Imaging Retina. 2015;46(6):643-648.

44. Cheung CS, Wong AW, Lui A, Kertes PJ, Devenyi RG, Lam WC. Incidence of endophthalmitis and use of antibiotic prophylaxis after intravitreal injections. Ophthalmology. 2012;119(8):1609-1614.

45. Falavarjani KG, Modarres M, Hashemi M, et al. Incidence of acute endophthalmitis after intravitreal bevacizumab injection in a single clinical center. Retina. 2013;33(5):971-974.

46. Falavarjani KG, Aghamirsalim M, Modarres M, et al. Endophthalmitis after resident-performed intravitreal bevacizumab injection. Can JOphthalmol. 2015;50(1):33-36.

47. Park Y, Kim KS, Park YH. Acute endophthalmitis after intravitreal injection and preventive effect of preoperative topical antibiotics. $\mathrm{JOCul}$ Pharmacol Ther. 2013;29(10):900-905.

48. Dossarps D, Bron AM, Koehrer P, et al. Endophthalmitis after intravitreal injections: incidence, presentation, management, and visual outcome. Am J Ophthalmol. 2015;160(1):17-25.

49. Ramel JC, Bron AM, Isaico R, et al. Incidence de l'endophtalmie après injection intravitréenne: peut-on se passer de l'antibioprophylaxie? [Incidence of endophthalmitis after intravitreal injection: is antibioprophylaxis mandatory?]. J Fr Ophthalmol. 2014;37(4):273-279. French.

50. Stone TW, Mittra RA, editors. ASRS 2013 Preferences and Trends Membership Survey. Available from: http://www.asrs.org/content/doc uments/_2013asrspatsurveyresults.pdf. Accessed August 6, 2015.

51. Stone TW, editor. ASRS 2014 Preferences and Trends Membership Survey. Available from: http://www.asrs.org/content/documents/_ 2014patsurvey-website-final.pdf. Accessed August 14, 2015.

52. Stone TW, editor. ASRS 2015 Preferences and Trends Membership Survey. Available from: http://www.asrs.org/content/documents/_2015pat-survey-results.pdf. Accessed August 14, 2015.
Clinical Ophthalmology

\section{Publish your work in this journal}

Clinical Ophthalmology is an international, peer-reviewed journal covering all subspecialties within ophthalmology. Key topics include: Optometry; Visual science; Pharmacology and drug therapy in eye diseases; Basic Sciences; Primary and Secondary eye care; Patient Safety and Quality of Care Improvements. This journal is indexed on Submit your manuscript here: http://www.dovepress.com/clinical-ophthalmology-journal

\section{Dovepress}

PubMed Central and CAS, and is the official journal of The Society of Clinical Ophthalmology (SCO). The manuscript management system is completely online and includes a very quick and fair peer-review system, which is all easy to use. Visit http://www.dovepress.com/ testimonials.php to read real quotes from published authors. 